\title{
Management of hydrocephalus in the patient with myelomeningocele: an argument against third ventriculostomy
}

\author{
Arthur E. Marlin, M.D., M.H.A. \\ Pediatric Neurosurgery of South Texas, PA, San Antonio, Texas
}

\begin{abstract}
The majority of children with myelomeningocele will have associated hydrocephalus. The management of hydrocephalus can be one of the most trying problems in this patient population. Cerebrospinal fluid (CSF) diversion will be required in these children for the remainder of their lives. Blockage of the outlets of the fourth ventricle and communication of the fourth ventricle with the central canal provides a mechanism for compensation. The signs and symptoms of CSF diversion malfunction, either shunt or third ventriculostomy, can be quite subtle. The objective indications of these malfunctions are less available after third ventriculostomy than when using mechanical shunting. The ease with which the diagnosis of malfunction can be made becomes the major advantage of mechanical shunting over third ventriculostomy.
\end{abstract}

KEY WORDS - hydrocephalus - myelomeningocele - third ventriculostomy - shunt

The majority of children with myelomeningocele will have associated hydrocephalus. ${ }^{18}$ The management of the hydrocephalus can be one of the most trying problems in this patient population. Cerebrospinal fluid diversion will be required in these children for their entire lives. Whether they are treated in the classic fashion with a ventricular shunt or a third ventriculostomy is performed, they will be dependent on CSF diversion..$^{15}$ There are several dilemmas in their treatment from timing of the initial shunt placement to the diagnosis and treatment of shunt malfunction or third ventriculostomy failure. These issues and the advantages of mechanical shunting over CSF diversion by third ventriculostomy will be discussed.

\section{PATHOPHYSIOLOGY}

Hydrocephalus can be simply defined as a condition in which CSF absorption is less than CSF production. ${ }^{7}$ It can obviously be the result of many causes. In children with myelomeningocele the Arnold-Chiari malformation or CM II is present as a result of the embryological and physiological factors associated with the development of myelomeningocele. The theories behind the association are beyond the scope of this article and remain debated. With CM II, the posterior fossa is small and the intradural contents of the upper cervical canal are tight. The hydrocephalus may be related to an aqueductal stenosis or due to

\footnotetext{
Abbreviations used in this paper: $\mathrm{CM}=$ Chiari malformation; $\mathrm{CSF}=$ cerebrospinal fluid; $\mathrm{CT}=$ computerized tomography; $\mathrm{ICP}=$ intracranial pressure; $\mathrm{MR}=$ magnetic resonance.
}

blockade of the outlets of the fourth ventricle. ${ }^{3}$ In addition venous abnormalities resulting from a small posterior fossa have also been suggested as a mechanism for the hydrocephalus. ${ }^{16}$ Whatever the cause when present it should be treated. Blockage of the outlets of the fourth ventricle and communication of the fourth ventricle with the central canal account for the common association of syringomyelia in this patient population (Fig. 1). This association allows for a mechanism of compensation of increased ICP with the hydrocephalus and after CSF diversion with shunt or third ventriculostomy failure. ${ }^{5,9,10,17}$

\section{TREATMENT}

A certain percentage of children with myelomeningocele, approximately $80 \%$, develop hydrocephalus. ${ }^{18}$ Frequently hydrocephalus is obvious at birth in the child with a myelomeningocele. In these cases some perform shunt placement as an initial step. ${ }^{3}$ If the signs of increased ICP are not present, then the ventricular system may be dilated on ultrasonography. If the myelomeningocele is open and leaking CSF, then the ventricles may be small. The initial step in the treatment of these children should be closure of the back. The incidence of ventriculitis is less if this is accomplished within the first 72 hours of life. Some would proceed with shunt placement at the same time; ${ }^{13}$ however, if the repair is delayed for more than 2 days, there is an increased incidence of shunt infection. ${ }^{6}$ It is my experience that if the closure is anatomical, that is, it includes a dural and muscle closure, CSF leakage is not a problem even in the face of gross hydrocephalus. 


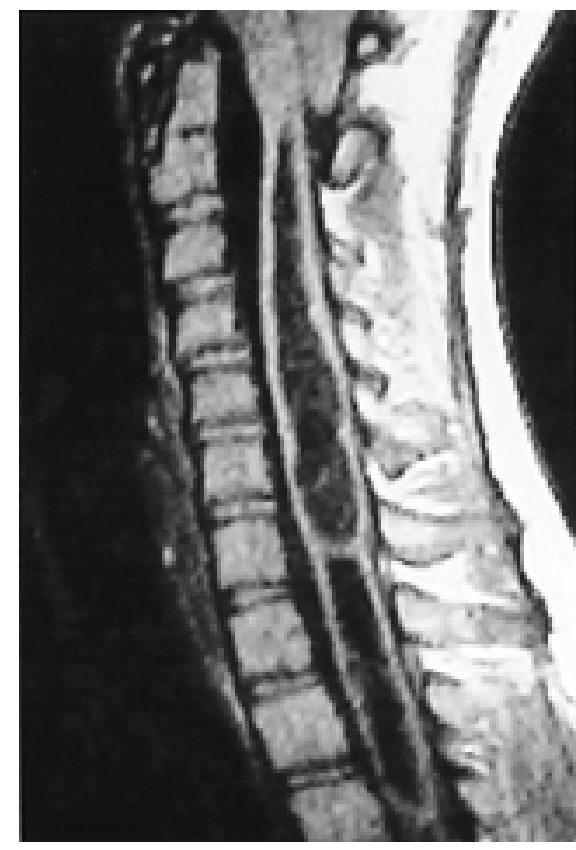

Fig. 1. An MR image obtained in a patient with myelomeningocele, CM, and syringomyelia. The obstruction of the outlets of the fourth ventricle and the communication with the central canal allows for the development of the syrinx.

Once CSF sterility is assured from final results of cultures obtained at closure, shunt placement may be performed. Ventricular peritoneal shunt placement is the initial procedure of choice. There is increasing evidence suggesting that the failure rate of third ventriculostomies is sufficient enough in infants that it should be more appropriately performed when the child is older. ${ }^{19}$ If there are abdominal problems such as perforation or peritonitis then an atrial shunt is placed. If hydrocephalus is not evident then the infant can be observed. Once, and if, hydrocephalus develops the infant should undergo shunt placement. Rekate ${ }^{16}$ has developed criteria in deciding which children should not undergo shunt treatment. These include cerebral mantle thickness greater than $3.5 \mathrm{~cm}$ and, at 5 months of age, normal development and no lower cranial nerve dysfunction.

Once a shunt is placed a more difficult problem is the management of its malfunction. In the majority of cases the signs and symptoms are the classic ones associated with increased ICP. These are headaches, vomiting, and lethargy. Because of the pathophysiology in myelomeningocele, however, compensation can occur with development of syringomyelia..$^{5,10,17}$ Thus the symptoms can be expanded to include those of syringomyelia and CM. Therefore in the patient with myelomeningocele it is imperative to assess shunt function before undertaking the treatment of either CM or syringomyelia, and even in fact, a tethered spinal cord. ${ }^{9,17}$ Because of an added ability to compensate, the signs and symptoms of shunt malfunction can be quite subtle. For example, it is not uncommon to have a subjective complaint of decreased performance in school and to find a significant increase in ventricular size on CT scans. Petit mal epilepsy, hyperactivity, and emotional disturbances have been linked to shunt malfunction in this population. Asymptomatic shunt malfunction is also common. In these children routine neurological follow up is mandatory. Annual ophthalmological evaluation is also recommended. When the physiological mechanisms for "compensation" have been exhausted, sudden respiratory or cardiac arrest can occur. There is an increased incidence of sudden death in children with myelomeningocele. ${ }^{15}$

At the time of shunt revision in a child whose sutures are closed, third ventriculostomy is a consideration. Although this may eliminate the need for a mechanical device, it does not eliminate the need for CSF diversion. At the time of third ventriculostomy a ventricular drain both to measure ICP and as a safety valve may be necessary. To keep the fenestration open initially some increased pressure may be needed. The initial literature in the new age of endoscopic third ventriculostomies suggests that the failure rate can be as high as 20 to $30 \%$. $^{2,19}$ If the third ventriculostomy closes, then the signs and symptoms of diversion malfunction can be expected to occur, but therein lies the problem. These signs and symptoms again may be quite subtle. ${ }^{2}$ Once the mechanical device has been removed, the family may think that there is no longer the need for a shunt. Education in this regard is extremely important because it can prevent an unnecessary death from diversion failure. ${ }^{8}$

If the third ventriculostomy fails then a decision to revise the third ventriculostomy or replace the shunt must be made. ${ }^{1}$ Although third ventriculostomy is certainly a reasonable alternative to mechanical shunting, especially in the patient in whom shunt placement is difficult, it is not the panacea that it was thought to be several years ago.

In this group of patients I prefer shunt placement for several reasons. First, after third ventriculostomy, although ICP may normalize, the ventricular system may not change in size. As the symptoms of shunt malfunction may be quite subtle, the diagnosis is more difficult. If in fact we go back to Rekate's criteria, ${ }^{16}$ when a shunt is present and the mantle is less than $3.5 \mathrm{~cm}$, the shunt should be revised. What now do we do when after third ventriculostomy the ventricles do not change in size? Magnetic resonance imaging criteria can be used to assess the patency of the stoma and some recommend that imaging be obtained yearly. ${ }^{4}$ Although MR imaging criteria are helpful, one still worries about insidious malfunction in this population. In the face of normal ICP we would think that the diversion is open but without a noninvasive mechanism to measure this, CSF management becomes more cumbersome.

The major advantage of third ventriculostomy over mechanical shunting is infection; thus, the decision about which technique to use will depend on the surgeon's or institution's infection rate statistics for mechanical shunting. Surgeries that I have performed produced a low rate of infection, now approximately $2 \%$. There are a variety of nonspecific factors that are believed to contribute to that infection rate. First and foremost is surgical experience. In addition the surgical isolation bubble is used with high-risk patients, traffic in the operating suite is limited, and the preparation of the skin is meticulous. There is minimal exposure and handling of the shunt. Preoperative antibiotic medications are given but are not really believed to be a significant factor. ${ }^{12}$ 
Mixter ${ }^{14}$ reported on the first endoscopic ventriculostomy in 1923. In the recent rediscovery of third ventriculostomy, early reports suggested that this was a cure for hydrocephalus. The advent of fiberoptic lighting and digital imaging with new endoscopic equipment made this old procedure very attractive. ${ }^{11}$ Although without doubt the new instrumentation has added to the neurosurgical armamentarium for the treatment of hydrocephalus, the cure has been elusive. There are more and more reports of third ventriculostomies failing. ${ }^{4}$ Revision of a third ventriculostomy is of course feasible but it adds greater risk and is more difficult than a mechanical shunt revision. It has been thought that the initial risk of third ventriculostomy was justified compared with the smaller risk over a longer period of time of mechanical shunting. This does not hold if there is dependency on the new diversion and the failure rate is significant. It has certainly been shown that there is dependency and that it does fail.

The most powerful argument in the choice of mechanical shunting over third ventriculostomy is the subtlety of the malfunctions and the complexity of the pathological entity. In the majority of cases when subtle signs and symptoms are present or when not, mechanical shunts are easy to evaluate: there may be a change in the physical characteristics of the shunt from the previous visit (refills quickly now as opposed to slowly 6 months prior); a surveillance or diagnostic CT scan reveals an increase in ventricular size; or x-ray films show a fracture in the tubing. Occasionally, in difficult-to-diagnose situations, some sort of flow or shunt study may need to be performed or even ICP monitoring may need to be undertaken. With third ventriculostomy the options are limited to less than perfect flow studies or ICP monitoring. The ease with which the diagnosis of malfunction can be made becomes the major advantage of one procedure over the other.

\section{CONCLUSIONS}

Although third ventriculostomy is seductive, mechanical shunting is more appropriate in the patients with myelomeningocele. This is because the pathophysiology of the conditions allows for some degree of compensation and thus subtle signs and symptoms of CSF diversion malfunction may be missed. The objective indications of these malfunctions are less available with third ventriculostomy than with mechanical shunting. The ease with which the diagnosis of malfunction can be made is a great advantage of one over the other.

\section{References}

1. Boschert J, Hellwig D, Krauss JK: Endoscopic third ventriculostomy for shunt dysfunction in occlusive hydrocephalus: long-term follow up and review. J Neurosurg 98:1032-1039, 2003

2. Cinalli G, Sainte-Rose C, Chumas P, et al: Failure of third ventriculostomy in the treatment of aqueductal stenosis in children. J Neurosurg 90:448-454, 1999
3. Cohen AR, Robinson S: Early management of myelomeningocele, in McLone DG (ed): Pediatric Neurosurgery: Surgery of the Developing Nervous System, ed 4. Philadelphia: WB Saunders, 2001, pp 241-260

4. Crone KR, Manwaring KH: Neuroendoscopy, in McLone DG (ed): Pediatric Neurosurgery: Surgery of the Developing Nervous System, ed 4. Philadelphia: WB Saunders, 2001, pp 548-557

5. Epstein F, Marlin AE, Hochwald G, et al: Myelomeningocele: a progressive intra-uterine disease. Dev Med Child Neurol Suppl 37:12-15, 1976

6. Gamache F Jr: Treatment of hydrocephalus in patients with meningomyelocele or encephalocele: a recent series. Childs Nerv Syst 11:487-488, 1995

7. Gaskill SJ, Marlin AE: Handbook of Pediatric Neurology and Neurosurgery. Boston: Little \& Brown, 1993, pp 57-60

8. Hader WJ, Drake J, Cochrane D, et al: Death after late failure of third ventriculostomy in children. Report of three cases. J Neurosurg 97:211-215, 2002

9. Hall PV, Lindseth RE, Cambell R, et al: Scoliosis and hydrocephalus in myelocele patients. The effects of ventricular shunting. J Neurosurg 50:174-178, 1979

10. Hochwald GM, Marlin AE, Wald A: Increases in ICP and development of plateau waves in decompensated hydrocephalic cats: a new model, in Beks JWF, Bosch DA, Brock M (eds): Intracranial Pressure III. Berlin: Springer-Verlag, 1976, pp 37-41 (Reference unverified)

11. Jones RF, Kwok BC, Stening WA, et al: The current status of endoscopic third ventriculostomy in the management of noncommunicating hydrocephalus. Minim Invasive Neurosurg 37:28-36, 1994

12. Marlin AE, Gaskill SJ: The use of the surgical isolation bubble in ventricular peritoneal shunts. Concepts Pediatr Neurosurg 11:47-53, 1991

13. Miller PD, Pollack IF, Pang D, et al: Comparison of simultaneous versus delayed ventriculoperitoneal shunt insertion in children undergoing myelomeningocele repair. J Child Neurol 11: 370-372, 1996

14. Mixter WJ: Ventriculoscopy and puncture of the floor of the third ventricle. Preliminary report of a case. Boston Med Surg J 188:277-278, 1923

15. Rekate HL: Management of hydrocephalus and the erroneous concept of shunt independence in spina bifida patients. BNI Q 4:17-20 1988

16. Rekate HL: To shunt or not to shunt: hydrocephalus and dysraphism. Clin Neurosurg 32:593-607, 1985

17. Reigel DH, Ammerman RT, Rotenstein D: Health care of the adult with spina bifida, in McLone DG (ed): Pediatric Neurosurgery: Surgery of the Developing Nervous System, ed 4. Philadelphia: WB Saunders, 2001, pp 266-278

18. Rintoul NE, Sutton LN, Hubbard AM, et al: A new look at myelomeningoceles: functional level, vertebral level, shunting, the implications for fetal intervention. Pediatrics 109:409-413, 2002

19. Teo C, Jones R: Management of hydrocephalus by endoscopic third ventriculostomy in patients with myelomeningocele. Pediatr Neurosurg 25:57-63, 1996

Manuscript received November 15, 2003.

Accepted in final form January 7, 2004.

Address reprint requests to: Arthur E. Marlin, M.D., M.H.A., 4499 Medical Drive, Suite 397, San Antonio, Texas 78229. email: aem@pediatric-neurosurgery.com. 